\title{
CORRESPONDENCE
}

tion in detecting patient-ventilator asynchrony. Crit Care Med 2011;39(11):24522457.

11. Sinderby C, Beck J. Neurally adjusted ventilatory assist. In: Tobin MJ, editor. Principles and practice of mechanical ventilation, 3rd edition. New York: McGraw-Hill Medical; 2013:351-375.

12. Sinderby C, Beck J. Neurally adjusted ventilatory assist (NAVA) in non-invasive ventilation. Minerva Anestesiol 2013;79(8): 915-925.

13. Ferreira F, Vincent JL, Brun-Buisson C, Sprung C, Sibbald W, Cook D. Doctors' perceptions of the effects of interventions tested in prospective, randomised, controlled, clinical trials: results of a survey of ICU physicians. Intensive Care Med 2001; 27(3):548-554.

14. Ospina-Tascón GA, Cordioli RL, Vincent JL. What type of monitoring has been shown to improve outcomes in acutely ill patients? Intensive Care Med 2008;34(5):800-820.

15. Ospina-Tascón GA, Büchele GL, Vincent JL. Multicenter, randomized, controlled trials evaluating mortality in intensive care: doomed to fail? Crit Care Med 2008;36(4): 1311-1322.

16. Briel M, Meade MO, Mercat A, Brower RG, Talmor D, Walter SD, et al. Higher vs lower positive end-expiratory pressure in patients with acute lung injury and acute respiratory distress syndrome: systematic review and meta-analysis. JAMA 2010; 303(9):865-873

17. Mireles-Cabodevila E, Hatipoglu U, Chatburn RL. A rational framework for selecting modes of ventilation. Respir Care 2013;58(2):348-366.

DOI: $10.4187 /$ respcare.02643

\section{Neurally Adjusted Ventilatory Assist: Insufficient Evidence of Broad Clinical Outcomes-Reply}

In reply:

Responding to my editorial ${ }^{1}$ that accompanied the research by Delisle et al, ${ }^{2}$ Sinderby raises 3 main questions. First, Sinderby asks why I summarize the outcome of the study with: "What is the clinical importance of this study; the 'So what?' if you will." A well designed physiological study such as that by Delisle et $\mathrm{al}^{2}$ provides essential evidence of a treatment's functional effects. Table 1 identifies other primary research that has identified statistically significant changes relevant to the implementation of neurally adjusted ventilatory assist (NAVA) and to the care of critically ill patients.

Table 1. Variables Demonstrating a Statistically Significant Difference in Primary Research Comparing NAVA to an Alternative Ventilation Strategy

\begin{tabular}{|c|c|c|}
\hline First Author & Year & Outcome Variables With Statistically Significant Differences \\
\hline Alander ${ }^{3}$ & 2012 & Asynchrony time, peak inspiratory pressure, breathing frequency \\
\hline Beck $^{4}$ & 2009 & Neural expiratory time, breathing frequency \\
\hline Bengtsson $^{5}$ & 2010 & $\begin{array}{l}\text { Peak airway pressure, breathing frequency, trigger synchrony, } \\
\text { cycle synchrony }\end{array}$ \\
\hline Bertrand $^{6}$ & 2013 & EAdi, trigger delay, asynchrony index \\
\hline Bordessoule $^{7}$ & 2012 & $\begin{array}{l}\text { Trigger delay, cycle asynchrony, asynchrony index, coefficient of } \\
\text { variation }\end{array}$ \\
\hline Brander $^{8}$ & 2009 & Mean airway pressure, tidal volume, breathing frequency \\
\hline Breatnach $^{9}$ & 2010 & Trigger synchrony, cycle synchrony, peak airway pressure \\
\hline Cammarota $^{10}$ & 2011 & $\begin{array}{l}\text { Mechanical expiratory time, inspiratory time, duty cycle, time } \\
\text { synchrony, asynchrony index }\end{array}$ \\
\hline Clement $^{11}$ & 2011 & Trigger delay, ventilator response time, pressure-time product \\
\hline Coisel $^{12}$ & 2010 & $\begin{array}{l}\mathrm{P}_{\mathrm{aO}} / \mathrm{F}_{\mathrm{IO}} ; \text { tidal volume; variability of airway pressure, tidal } \\
\text { volume, and minute ventilation; EAdi }\end{array}$ \\
\hline Colombo $^{13}$ & 2008 & Tidal volume, breathing frequency, asynchrony index \\
\hline Lee $^{14}$ & 2012 & Peak inspiratory pressure, work of breathing \\
\hline Moerer $^{15}$ & 2008 & Patient-ventilator synchrony, trigger effort, breathing comfort \\
\hline de la Oliva ${ }^{16}$ & 2012 & Asynchrony index, EAdi, tidal volume, COMFORT score \\
\hline Piquilloud $^{17}$ & 2012 & Trigger delay, asynchrony index \\
\hline Piquilloud $^{18}$ & 2011 & $\begin{array}{l}\text { Trigger delay, inspiratory time in excess, total asynchrony events, } \\
\text { number of patients with asynchrony index }>10 \% \text {, ineffective } \\
\text { trigger effort events, late cycling events, premature cycling } \\
\text { events, double triggering }\end{array}$ \\
\hline Schmidt $^{19}$ & 2012 & $\begin{array}{l}\text { Trigger delay, inspiratory time in excess, asynchrony index, } \\
\text { asynchrony index influenced by leaks }\end{array}$ \\
\hline Schmidt $^{20}$ & 2010 & Variability of flow, variability of breathing pattern \\
\hline Spahija $^{21}$ & 2010 & Trigger delay, cycle delay \\
\hline Terzi $^{22}$ & 2010 & Tidal volume, asynchrony index \\
\hline
\end{tabular}

EAdi $=$ electrical activity of the diaphragm

As the body of the physiological evidence relating to NAVA has grown, authors and researchers have hypothesized expected clinical outcomes, such as a decreased number of ventilator days ${ }^{16}$ and decreased ICU stay and hospital stay. ${ }^{23} \mathrm{~A}$ smaller number of studies have investigated any association between patient-ventilator synchrony and clinical outcomes. Two projects have identified an association between patient-ventilator trigger asynchrony and longer duration of mechanical ventilation. ${ }^{24,25}$ De Wit et al demonstrated an association between ineffective triggering and longer duration of mechanical ventilation, longer ICU and hospital stay, and a reduced likelihood of discharge to home. ${ }^{26}$ De Wit et al have also identified a statistically significant relationship between ineffective triggering index and deeper sedation level: a finding that may result in false conclusions of weaning intolerance and longer duration of mechanical ventilation. ${ }^{27} \mathrm{~A}$ recent study including adult trauma subjects identified no association between patient-ventilator synchrony and ventilator days, ICU and hospital stay, proportion of subjects who were discharged to home, or mortality. ${ }^{28}$

I certainly acknowledge that consistently demonstrated outcomes of NAVA (such as enhanced patient-ventilator synchrony) also happen to be those factors identified with desired clinical outcomes (such as a reduced number of ventilator days), though I have identified no studies to date that have investigated a direct link between the two. Though preliminary research outcomes related to NAVA are promising, well designed studies are needed to directly measure clinical outcomes. 3,6,7,10,12,13,17-20,22,25,29-31

Referring to the failure of conventional ventilators to provide ventilation synchronous with patient efforts, Sinderby asks, "is it not in the best interest of respiratory therapists to reduce this problem?" I would respond with a resounding Yes! Respiratory 
Table 2. Purchase Price of NAVA-Ready Servo-i Ventilator and EAdi Catheter

\begin{tabular}{lrr}
\hline \hline & Unit Price & 12 Units \\
\hline $\begin{array}{l}\text { NAVA-ready Servo-i Universal Extended Edition Ventilator, } \\
\quad \text { including freight charges }\end{array}$ & $\$ 68,628$ & $\$ 823,546$ \\
EAdi catheter: 12 French, $125 \mathrm{~cm}, 5$ per package & $\$ 1,188$ & $\$ 14,256$ \\
Total & $\$ 69,816$ & $\$ 837,802$ \\
& & \\
\hline NAVA $=$ neurally adjusted ventilatory assist & & \\
EAdi $=$ electrical activity of the diaphragm & & \\
\hline
\end{tabular}

Table 3. Purchase Price of NAVA Software and Accessory Hardware Upgrade

\begin{tabular}{lcr}
\hline \hline & Unit Price & 12 Units \\
\hline $\begin{array}{l}\text { NAVA Software, NIV NAVA Software, Edi module } 60 \mathrm{~Hz}, \\
\quad \text { including freight charges }\end{array}$ & $\$ 14,999$ & $\$ 179,988$ \\
$\begin{array}{l}\text { EAdi catheter: } 12 \text { French, } 125 \mathrm{~cm}, 5 \text { per package } \\
\text { Total }\end{array}$ & $\$ 1,188$ & $\$ 14,256$ \\
\hline $\begin{array}{l}\text { NAVA }=\text { neurally adjusted ventilatory assist } \\
\text { EAdi }=\text { electrical activity of the diaphragm }\end{array}$ & $\$ 16,187$ & $\$ 194,244$ \\
& & \\
\hline
\end{tabular}

therapists are on the front lines, witnessing trigger, cycle, and flow asynchrony at the bedside every day. We have also, however, been party to the premature application of intermittent positive pressure ventilation: a technology that seemed to make sense but that eventually was rejected for lack of evidence of improved clinical outcomes.

The primary interest of respiratory therapists is patient safety. NAVA has been granted regulatory approval by the United States Food and Drug Administration, and evidence suggests NAVA can be employed safely with neonatal, infant, pediatric, and adult populations. Since primary safety considerations have been addressed, economic considerations are relative to Sinderby's question. NAVA is currently licensed to a single ventilator manufacturer: Maquet Medical Systems. Table 2 indicates expenses related to the purchase of one NAVA-ready Servo-i ventilator and 12 NAVA-ready Servo-i ventilators: the mean number of ventilators owned by acute care hospitals in the United States. ${ }^{32}$ Table 3 indicates costs relating to the purchase of NAVA software and accessory hardware for facilities that already own Servo-i ventilators. Additional departmental expenses would include time for staff training and equipment maintenance. ${ }^{11}$ Considering that the United States gross domestic product used by critical care medicine recently increased by $13.7 \%, 33$ considering the unique challenges associated with cost containment in critical care, ${ }^{34}$ and considering that federal funding from the Centers for Medicare and Medicaid Services in the United States is increasingly dependent upon demonstrated effectiveness of therapeutic interventions, using technology without demonstrated improvement of patient outcomes imposes fiscal risk related to uncertain future reimbursement.

The best interests of respiratory therapists also consider the sleep quality of our patients. In addition to addressing the problem of patient-ventilator asynchrony, the research by Delisle et $\mathrm{al}^{2}$ addresses a deficit in our understanding of sleep disturbances in the ICU. ${ }^{35}$ Pressure support ventilation (PSV) in particular has been examined as an alternative approach to reducing apnea and improving sleep quality of mechanically ventilated patients. Roche-Campo et al studied tracheostomized subjects and concluded that PSV was associated with a higher total sleep time than spontaneous ventilation, though they identified no significant differences in measures of sleep quality. ${ }^{36} \mathrm{Ca}-$ bello et al examined clinician-adjusted PSV, automatically adjusted PSV, and continuous mandatory ventilation, and identified no statistically significant differences among the interventions with regard to rapid-eyemovement (REM) sleep duration, fragmentation index, number of ineffective breath efforts, or central apneas. ${ }^{37}$ When PSV was used as a common comparison, improvements related to sleep have been demonstrated with other mechanical ventilation strategies, including: proportional assist ventilation (decreased patient-ventilator asynchrony events, ${ }^{38,39}$ decreased sleep fragmentation, ${ }^{39}$ increased REM sleep time, ${ }^{39}$ increased slow wave sleep time ${ }^{39}$ ), NAVA (increased REM sleep time, decreased sleep fragmentation index, decreased ineffective breath efforts, decreased frequency of central apnea),,$^{40}$ titration of PSV to inspiratory muscle effort at night (improved gas exchange, increased sleep efficiency, increased REM sleep, decreased ineffective breath efforts), ${ }^{41}$ and continuous mandatory ventilation (decreased arousals and awakenings, decreased central apneas). ${ }^{42}$ All studies were insufficiently powered (sample size range 9-16) to yield statistically significant, generalizable findings. None included consideration of broad clinical outcomes.

Sinderby states, "To suggest that only outcome data from randomized controlled trials are required before new modes can be used simply perpetuates a myth and blinds us to other approaches to rationally selecting the best treatment options." In point of fact, the 2 primary suggestions of my editorial were: there is insufficient evidence of improved outcomes with NAVA, and until improved outcomes are demonstrated, clinical managers are unlikely to invest in NAVA.

Sinderby's final comments and questions relate to the methodological challenges of randomized controlled trials (RCTs), and echo concerns specific to RCTs in the critical care environment, which have been articulated by Vincent. ${ }^{43}$ Because well designed RCTs permit cause-and-effect conclusions, they are likely to remain the gold standard of experimental research methods in healthcare research, despite the fact that they are fraught with challenges. Three of the challenges enumerated by Vincent are particularly relevant to the application of NAVA in the critical care environment. First, adequately powered research will likely require multiple research centers and a lengthy enrollment period. Second, statistically significant differences are more likely to be identified if the study subjects are at greater risk of patient-ventilator asynchrony, and the literature suggests this distinction would include pediatric patients ${ }^{3,7}$ and patients with COPD. ${ }^{11,17,21,24,44}$ Third, end points should be chosen carefully, and we might give special consideration to the current healthcare reimbursement context. Despite these challenges, I would join with the authors of multiple smaller physiologic studies $3,6,7,10,13,17-20,22,23,26-28$ to call for ap- 
propriately powered, prospective RCTs comparing the effects of conventional ventilation and NAVA on important patient outcomes, especially given the promising research on NAVA in the past decade.

Kathy S Myers Moss MEd RRT-ACCS

Department of Cardiopulmonary and Diagnostic Sciences University of Missouri Columbia, Missouri

The author has disclosed no conflicts of interest.

\section{REFERENCES}

1. Moss KS. Neurally adjusted ventilatory assist: insufficient evidence of broad clinical outcomes (editorial). Respir Care 2013; 58(5):884-885.

2. Delisle S, Terzi N, Ouellet P, Bellemare P, Tetrault J-P, Arsenault P. Effect of ventilatory variability on occurrence of central apneas. Respir Care 2013;58(5):745-753.

3. Alander M, Paltoniemi O, Pokka T, Kontiokari T. Comparison of pressure-, flow-, and NAVA-triggering in pediatric and neonatal ventilatory care. Pediatr Pulmonol 2012;47(1):76-83.

4. Beck J, Reilly M, Grasselli G, Mirabella L, Slutsky AS, Dunn MS, Sinderby C. Patient-ventilator interaction during neurally adjusted ventilatory assist in low birth weight infants. Pediatr Res 2009; 65(6):663-8. DOI: 10.1203/PDR.0b013e 31819e72ab.

5. Bengtsson JA, Edberg KE. Neurally adjusted ventilatory assist in children: an observational study. Pediatr Crit Care Med. 2010 Mar;11(2):253-7. DOI: 10.1097/ PCC.0b013e3181b0655e.

6. Bertrand P-M, Futier E, Coisel Y, Matecki S, Jaber S, Constantin J-M. Neurally adjusted ventilatory assist vs pressure support ventilation for noninvasive ventilation during acute respiratory failure. Chest 2013; 143(1):30-36.

7. Bordessoule A, Emeriaud G, Morneau S, Jouvet P, Beck J. Neurally-adjusted ventilatory assist improves patient-ventilator interaction in infants as compared with conventional ventilation. Pediatr Res 2012; 72(2): 194-202.

8. Brander L, Leong-Poi H, Beck J, Brunet F, Hutchison SJ, Slutsky AS, et al. Titration and implementation of neurally adjusted ventilatory assist in critically ill patients. Chest 2009;135(3):695-703. DOI: 10.1378/ chest.08-1747.

9. Breatnach C, Conlon NP, Stack M, Healy M, O'Hare BP. A prospective crossover comparison of neurally adjusted ventilatory assist and pressure-support ventilation in a pediatric and neonatal intensive care unit population. Pediatr Crit Care Med 2010; 11(1):7-11. DOI: $10.1097 / \mathrm{PCC} .0 \mathrm{~b} 013 \mathrm{e}$ 3181b0630f.

10. Cammarota G, Olivieri C, Costa R, Vaschetto R, Colombo D, Turucz E, et al. Noninvasive ventilation through a helmet in postextubation hypoxemic patients: physiologic comparison between neurallyadjusted ventilatory assist and pressure support ventilation. Intensive Care Med 2011; 37(12):1943-1950.

11. Clement KC, Thurman TL, Holt SJ, Heulitt MJ. Neurally triggered breaths reduce trigger delay and improve ventilator response times in ventilated infants with bronchiolitis. Intensive Care Med 2011;37(11):1826-1832.

12. Coisel Y, Chanques G, Jung B, Constantin J-M, Capdevila X, Matecki S, et al. Neurally adjusted ventilatory assist in critically ill postoperative patients: a crossover randomized study. Anesthesiology 2010; 113(4):925-935.

13. Colombo D, Cammarota G, Bergamaschi V, De Lucia M, Della Corte F, Navalesi P. Physiologic response to varying levels of pressure support and neurally adjusted ventilatory assist in patients with acute respiratory failure. Intensive Care Med 2008; 34(11):2010-2018.

14. Lee J, Kim H-S, Sohn JA, Lee JA, Choi $\mathrm{CW}$, Kim E-K, et al. Randomized crossover study of neurally adjusted ventilatory assist in preterm infants. J Pediatr 2012; 161(5):808-813. DOI: 10.1016/j.jpeds. 2012.04.040.

15. Moerer O, Beck J, Brander L, Costa R, Quintel M, Slutsky AS, et al. Subject-ventilator synchrony during neural versus pneumatically triggered non-invasive helmet ventilation. Intensive Care Med 2008;34(9): 1615 1623. DOI: 10.1007/s00134-008-1163-z.

16. de la Oliva P, Schuffelmann C, GomezZamora A, Villar J, Kacmarek RM. Asynchrony, neural drive, ventilatory variability and COMFORT: NAVA versus pressure support in pediatric patients. A non-randomized cross-over trial. Intensive Care Med 2012;38(5):838-846.

17. Piquilloud L, Tassaux D, Bialais E, Lambermont B, Sottiaux T, Roeseler J, et al. Neurally-adjusted ventilatory assist (NAVA) improves patient-ventilator interaction during non-invasive ventilation delivered by face mask. Intensive Care Med 2012;38(10):1624-1631.

18. Piquilloud L, Vignaux L, Bialais E, Roeseler J, Sottiaux T, Laterre P-F, et al. Neurally adjusted ventilatory assist improves patient-ventilator interaction. Intensive Care Med 2011;37(2):263-271.

19. Schmidt M, Dres M, Raux M, DeslandesBoutmy E, Kindler F, Mayaux J, et al. Neurally-adjusted ventilatory assist improves patient-ventilator interaction during postextubation prophylactic noninvasive ventilation. Crit Care Med 2012;40(6):1738-1744.

20. Schmidt M, Demoule A, Cracco C, Gharbi A, Fiamma M-N, Straus C, et al. Neurallyadjusted ventilatory assist increases respiratory variability and complexity in acute respiratory failure. Anesthesiol 2010; 112(3):670-681.

21. Spahija J, de Marchie M, Albert M, Bellemare P, Delisle S, Beck J, et al. Patient-ventilator interaction during pressure support ventilation and neurally adjusted ventilatory assist. Crit Care Med 2010;38(2):519-526.

22. Terzi N, Pelieu I, Guittet L, Ramakers M, Seguin A, Daubin C, et al. Neurally-adjusted ventilatory assist in patients recovering spontaneous breathing after acute respiratory distress syndrome: physiological evaluation. Crit Care Med 2010;38(9):1830-1837.

23. Sinderby C, Navalesi P, Beck J, Skrobik Y, Comtois N, Friberg S, et al. Neural control of mechanical ventilation in respiratory failure. Nat Am 1999;5(12):1433-1436.

24. Chao DC, Scheinhorn DJ, Stearn-Hassenpflug M. Patient-ventilator trigger asynchrony in prolonged mechanical ventilation. Chest 1997;112(6):1592-1599.

25. Thille AW, Rodriguez P, Cabello B, Lellouche F, Brochard L. Patient-ventilator asynchrony during assisted mechanical ventilation. Intensive Care Med 2006;32(10): 1515-1522.

26. de Wit M, Miller KB, Green DA, Ostman HE, Gennings C, Epstein SK. Ineffective triggering predicts increased duration of mechanical ventilation. Crit Care Med 2009;37(10):2740-2745.

27. de Wit M, Pedram S, Best AM, Epstein SK. Observational study of patient-ventilator asynchrony and relationship to sedation level. J Crit Care 2009;24(1):74-80.

28. Robinson BR, Blakeman T, Toth P, Hanseman DJ, Mueller E, Branson R. Patientventilator asynchrony in a traumatically injured population. Respir Care 2013 [Epub ahead of print].

29. Kacmarek RM. Proportional assist ventilation and neurally adjusted ventilatory assist. Respir Care 2011;56(2):140-152.

30. Williams K, Hinojosa-Kurtzberg M, Parthasarathy S. Control of breathing during mechanical ventilation: who is the boss? Respir Care 2011;56(2):127-139.

31. Branson RD, Blakeman TC, Robinson BR. Asynchrony and dyspnea. Respir Care 2013;58(6):973-989.

32. Rubinson L, Vaughn F, Nelson S, et al. Mechanical ventilators in US acute care hospitals. Disaster Med Public Health Prep 2010;4(3):199-206.

33. Halpern NA, Pastores SM. Critical care medicine in the United States 2000-2005: an analysis of bed numbers, occupancy 
rates, payer mix, and costs. Crit Care Med 2010;38(1):65-71.

34. Halpern NA. Can the costs of critical care be controlled? Curr Opin Crit Care 2009; 15(6):591-596.

35. Boyko Y, Ording H, Jennum P. Sleep disturbances in critically ill patients in ICU: how much do we know? Acta Anaesthesiol Scand 2012;56(8):950-958.

36. Roche-Campo F, Thille AW, Drouot X, Galia F, Margarit L, Cordoba-Izquierdo A, et al. Comparison of sleep quality with mechanical versus spontaneous ventilation during weaning of critically ill tracheostomized patients. Crit Care Med 2013;41(7): 1637-1644.

37. Cabello B, Thille AW, Drouot X, Galia F, Mancebo J, d'Ortho M-P, et al. Sleep quality in mechanically ventilated patients: comparison of three ventilatory modes. Crit Care Med 2008;36(6):1749-1755.

38. Alexopoulou C, Kondili E, Plataki M, Georgopoulos D. Patient-ventilator synchrony and sleep quality with proportional assist and pressure support ventilation. Intensive Care Med 2013;39(6):1040-1047.

39. Bosma K, Ferreyra G, Ambrogio C, Pasero D, Mirabella L, Braghiroli A, et al. Patientventilator interaction and sleep in mechanically ventilated patients: pressure support versus proportional assist ventilation. Crit Care Med 2007;35(4):1048-1054.

40. Delisle S, Ouellet P, Bellemare P, Tetrault J-P, Arsenault P. Sleep quality in mechanically ventilated patients: comparison between NAVA and PSV modes. Ann Intensive Care 2011;1(42):1-8.

41. Fanfulla F, Delmastro M, Berardinelli A, Lupo NDA, Nava S. Effects of different ventilator settings on sleep and inspiratory effort in patients with neuromuscular disease. Am J Respir Crit Care Med 2005; 172(5):619-624.

42. Parthasarathy S, Tobin MJ. Effect of ventilator mode on sleep quality in critically ill patients. Am J Respir Crit Care Med 2002; 166(11):1423-1429.

43. Vincent J-L. We should abandon randomized controlled trials in the intensive care unit. Crit Care Med 2010;38(10):S534S538.

44. Nava S, Bruschi C, Fracchia C, Braschi A, Rubini F. Patient-ventilator interaction and inspiratory effort during pressure support ventilation in patients with differrent pathologies. Eur Respir J 1997; 10(1):177-183.

DOI: $10.4187 /$ respcare.02818

\section{The Whisper Game}

\section{To the Editor:}

There is an interesting game called "telephone" or "whispers," in which a message is passed on, in a whisper, down a line of people, and then the last person speaks the message out loud. The final version of the message is usually radically changed from the original. Reference to this game is sometimes used to call attention to distorted information in research papers.

In the July issue of ResPiRATORy CARE, Mark Siobal and colleagues presented an elaborate and well conducted study comparing ventilatory volumetric capnography to other methods. ${ }^{1}$ While I am reluctant to criticize such a good paper, some minor mathematical errors crept in that reminded me of the whisper game.

In the Discussion section, on page 1149, the important equation relating the partial pressure of $\mathrm{CO}_{2}$ in arterial blood, $\mathrm{CO}_{2}$ production, and minute alveolar ventilation is presented as:

$$
\mathrm{P}_{\mathrm{aCO}_{2}}=\dot{\mathrm{V}}_{\mathrm{CO}_{2}} / \dot{\mathrm{V}}_{\mathrm{A}}
$$

A simple dimensional analysis shows that this equation is wrong (a whisper error?) The left hand side of the equation has units of pressure, but the right hand side of the equation is dimensionless (ie, units of flow in the numerator cancel units of flow in the denominator). The correct version of this equation is:

$$
\mathrm{P}_{\mathrm{aCO}_{2}} \propto \dot{\mathrm{V}}_{\mathrm{CO}_{2}} / \dot{\mathrm{V}}_{\mathrm{A}}
$$

where the symbol, $\propto$ means "is proportional to." In Siobal's paper ${ }^{1}$ the equation also appears in Figure 7 (same page), and they reference a paper by Tusman et al, ${ }^{2}$ who give a simplified version of the equation:

$$
\mathrm{P}_{\mathrm{aCO}_{2}}=\left(\mathrm{K} \times \mathrm{V}_{\mathrm{CO}_{2}}\right) / \dot{\mathrm{V}}_{\mathrm{A}}
$$

where $\mathrm{K}$ is called "a constant" without further explanation. (Note that the above equation from the paper has a typo: it is missing the dot over the $\mathrm{V}$ in the numerator. The dot is a mathematical symbol denoting the derivative, in this case meaning the change in volume with respect to time: ie, flow).

The traditional and more useful form of the equation is:

$$
\mathrm{P}_{\mathrm{aCO}_{2}}=\left(0.863 \times \dot{\mathrm{V}}_{\mathrm{CO}_{2}}\right) / \dot{\mathrm{V}}_{\mathrm{A}}
$$

where $\mathrm{P}_{\mathrm{aCO}_{2}}=$ arterial carbon dioxide tension ( $\mathrm{mm} \mathrm{Hg}$ ), $\dot{\mathrm{V}}_{\mathrm{CO}_{2}}=$ carbon dioxide production $(\mathrm{mL} / \mathrm{min})$, and $\dot{\mathrm{V}}_{\mathrm{A}}=$ alveolar ventilation $(\mathrm{L} / \mathrm{min})$.
The factor 0.863 converts concentration to partial pressure and also corrects for the fact that $\mathrm{CO}_{2}$ production is usually expressed at standard temperature and pressure dry (STPD), whereas alveolar ventilation is expressed at body temperature and pressure saturated (BTPS). ${ }^{3}$ I contend that this form is more useful because it allows actual calculations using real or simulated data.

Another whisper error: Siobal et al present the graphic shown in Figure 1 (their Fig. 8). In this figure, the quantity $\mathrm{V}_{\mathrm{D} \text {-alv }}$ is represented as the "shaded areas" between the volume curve and the $\mathrm{CO}_{2}$ axis. Although the vertical axis is labeled simply $\mathrm{CO} 2$, there are horizontal lines labeled $\mathrm{P}_{\mathrm{aCO}}$, $\mathrm{P}_{\mathrm{ACO}_{2}}$, et cetera, implying that the unit of measurement for the vertical axis is $\mathrm{mm} \mathrm{Hg}$. The reference is again the paper by Tusman et al. ${ }^{2}$ Out of curiosity, I looked up that paper and found a very similar graphic (Fig. 2). Note that in Figure 2 the volume axis is labeled in units of $\mathrm{mL}$, and the $\mathrm{CO}_{2}$ axis is labeled in units of $\mathrm{mm} \mathrm{Hg}$. This is ok for graph B, because all the points on the graph are either volumes or pressures. But it is not ok for graph $\mathrm{A}$. As with the first equation I mentioned, labeling the $\mathrm{CO}_{2}$ axis in units of pressure is incorrect, based on a simple dimensional analysis. The areas indicated are supposed to be volumes, but the units of those areas would be $\mathrm{mL} \times \mathrm{mm} \mathrm{Hg}$. The problem is that this figure got corrupted when it was "whispered" from its original source.

In that source, Fowler ${ }^{4}$ showed the vertical axis as $\mathrm{CO}_{2}$ concentration expressed as a fraction. Fletcher et al, ${ }^{5}$ who were referenced by Tusman et al, ${ }^{2}$ seem to have written the original article describing volumetric $\mathrm{CO}_{2}$ monitoring. They showed several graphs of volume versus fraction of $\mathrm{CO}_{2}$. Area in units of a fraction times volume yields the units of volume, as required. Tusman et al even state explicitly "The advantage of using fractions of carbon dioxide compared with partial pressure is that each area represents a volume of carbon dioxide, real or theoretical."'2

You may think the above issues are trivial matters, not worth mentioning. If you are a clinician whose main interest is basic concepts, perhaps you would be right. But if you were a researcher trying to analyze raw data, an educator trying to make a simulation with a spreadsheet, or an engineer trying to design software for a monitor, these errors could be quite confusing if you were new to the subject. 